\title{
O MOVIMENTO OPERÁRIO E A FORMAÇAO DO TRABALHADOR
}

\author{
Luiz Inácio Gaiger* \\ Daniela de Oliveira**
}

SÍNTESE - O artigo tem como foco a participação das organizações operárias na formação educacional do trabalhador rio-grandense. Com base na análise de obras repertoriadas sobre o tema, identifica, de um lado, os aspectos em destaque na bibliografia e, de outro, as experiências operárias mais significativas para a formação do trabalhador. Centra-se na Primeira República, revisando a literatura e caracterizando as práticas pedagógicas e a influência das correntes anarquistas.

PALAVRAS-CHAVE - movimento operário e formação do trabalhador.
ABSTRACT - The article focuses on the participation of the labor organizations in the education of the workers of Rio Grande do Sul. Based on the analysis of known works written on the subject, this article identifies, on the one hand, the aspects highlighted by the bibliography and, on the other hand, the most significant experiences for the education of the workers. It concentrates on time of the First Republic by reviewing the literature and characterizing the pedagogical practices, as well as the influence of the anarchical trends.

KEY WORDS - labourer moviment and education of the workers.

A formação dos trabalhadores urbanos no Rio Grande do Sul, vista como um processo de instauração e transmissão de saberes constitutivos de uma determinada noção de urbanidade e cidadania, teve nas organizações operárias um de seus vetores fundamentais. Ao lado da escola, da Igreja e da ação patronal, com as quais se colocaram por vezes em posição complementar, por vezes em posição conflitiva, as organizações operárias atuaram como agentes formadores da classe operária. Utilizando métodos de ação pedagogicamente diferenciados, com o objetivo de modificar as disposições culturais da base operária, as organizações de classe participaram da construção social de um saber teórico-prático que baliza a compreensão e a atitude dos trabalhadores diante da sociedade urbano-industrial rio-grandense, nos diferentes espaços-tempos transcorridos desde a Primeira República.

* Doutor em Sociologia, professor do Curso de Mestrado em Educação da Universidade do Vale do Rio dos Sinos (UNISINos). Coordenador do subprojeto Sindicalismo, práticas pedagógicas e formação operária.

** Graduanda em Ciências Sociais e bolsista de Iniciação Científica da Universidade do Vale do Rio dos Sinos (UNISINOS). 
Por essa razão, uma das linhas de estudo desenvolvida no âmbito do projeto Urbanidade e Cidadania direcionou-se a esse agente formador. Se historicamente sua ação efetivou-se, para a classe operária, num quadro de integração subordinada à sociedade emergente, é relevante considerar as peculiaridades de cada circunstância e época, identificando-se os momentos de inflexão e de ruptura dos modelos que orientaram a prática operária e modificaram o seu impacto formador sobre os trabalhadores. Importaria discernir as estratégias pedagógicas, implícitas ou explícitas, acionadas em práticas educativas concebidas com esse fim precípuo, em iniciativas de formação político-ideológica de massa, ou ainda no cotidiano das organizações operárias, no qual se estabelecem formas específicas de produção e de transmissão de saberes. Em particular, caberia verificar como esse agente formador se contrapôs à fábrica, entendida como uma instituição social concorrente, geradora de práticas e de representações que permeiam a compreensão do operário acerca da sua posição de classe e de sua inserção na sociedade.

A principal tarefa realizada nesse sentido, da qual aqui apresentam-se sucintamente alguns resultados, consistiu no levantamento e análise da bibliografia existente, com a finalidade de identificar as inflexões temáticas predominantes, discernir as lacunas e questões suscetíveis de originar novos objetos de pesquisa e criar um banco informatizado de fontes para uso da comunidade acadêmica. ${ }^{1}$

Sabia-se de antemão que os estudos na área se concentram no contexto industrial do eixo Rio-São Paulo (Petersen, 1995) e que são escassos os estudos direcionados ao papel dos sindicatos como um agente formador da classe operária ou que, mesmo tendo outro foco principal, abordam em algum momento a ação sindical por esse ângulo (Manfredi, 1996). Por isso, adotou-se uma grade de fichamento relativamente ampla, ao mesmo tempo em que se deu especial atenção aos estudos centrados no Rio Grande do Sul ou suscetiveis de conter, nas entrelinhas, informações pertinentes.

A abertura do leque temático ensejou a inclusão de obras sobre o processo de industrialização e sobre as relações de produção e trabalho no sistema fabril, com o predomínio de estudos de Sociologia e Economia e a presença de trabalhos sobre a região metropolitana de Porto Alegre e o Vale do Sinos. Desponta, nas obras repertoriadas, a preocupação com o impacto das transformações tecnológicas e no processo de trabalho sobre a subjetividade, as competências requeridas e as estratégias de qualificação dos trabalhadores. Esse parece ser, não sem razão, o tema que vem centralizando as atenções dos agentes sociais envolvidos com a realidade do trabalhador e com a sua formação, como profissional e cidadão.

Aproximando-nos da realidade operária, a consulta acerca de 220 obras comprova que as organizações operárias são vistas, na literatura em questão, sobretudo como um agente de mobilização e de representação política dos trabalhadores, e suas estratégias geralmente interpretadas em função de alterações no processo de trabalho e nas relações de classe. São abundantes $(36,9 \%)^{2}$ os estudos sobre as organizações e as mobilizações coletivas dos trabalhadores. A temática da subjeti-

1 O Banco Urbanidade e Cidadania é uma atividade conjunta do Projeto Integrado e deverá estar disponivel para consultas até o final de 1998.

2 Percentuais sobre um total de 209 fontes contabilizadas. 
vidade, referida ao debate clássico sobre a consciência de classe ou à questão mais recente da identidade operária, reúne diversos trabalhos (11\%) de Sociologia e Antropologia. As relações entre o ambiente da fábrica e a vida cotidiana dos trabalhadores permeiam outros estudos (4,3\%), não sendo incomum o recorte de gênero, geralmente aposto ao de classe.

Já o número de obras diretamente relacionadas ao foco da pesquisa é reduzido (10,5\%), havendo apenas seis estudos específicos sobre o Rio Grande do Sul. Com trabalhos tão esparsos, não se pode pretender que alguma região ou período histórico esteja coberto, ainda que parcialmente, ou mesmo que haja recorrência no tratamento de alguma temática particular. Percebe-se contudo que a literatura, no geral, divide-se entre trabalhos de cunho historiográfico, voltados às primeiras décadas do século Xx e cobrindo um período relativamente extenso, e trabalhos que problematizam situações contemporâneas, muitas vezes com base em estudos de caso. Aparece então um contraste entre estudos acerca das origens do espaço urbano-industrial e da gênese de seus agentes sociais e, por outro lado, estudos dos problemas e impasses com que se defrontam esses agentes na configuração atual daquele espaço.

O fato é revelador das mudanças na realidade operário-sindical e, principalmente, nos objetos de pesquisa. Quanto a esses, observa-se em destaque duas experiências, distantes no tempo e no entanto comparáveis por suas similitudes: a ação educativa libertária, do início do século, e o trabalho de formação sindical, em particular de orientação cutista, desenvolvido pelas correntes emergentes após o Regime Militar. Ambas se desenvolvem em contextos em que a autonomia cultural e política da classe operária ganha contornos históricos específicos, em sua luta contra a tutela estatal ou do aparelho político-partidário; ambas expressam uma valorização da cultura e da consciência como dimensões formadoras da classe operária e, a seu modo, produziram diversas iniciativas de educação dos trabalhadores.

Nos limites deste texto, destacaremos alguns aspectos relacionados ao estudo das ações do movimento anarquista, cuja presença marcou a realidade operária do Rio Grande do Sul durante a Primeira República.

O final do século XIX no Brasil assistiu a transformações que resultaram na instauração do regime republicano, na expansão da cafeicultura e na ascensão das oligarquias regionais. O café, principalmente, ao permitir a acumulação de capital e ensejar a modernização do sistema produtivo e comercial, estimulou as elites dirigentes a se investirem das idéias de progresso e civilização, ao mesmo tempo que o país assumia feições urbanas e as fábricas compunham um cenário peculiar nas incipientes cidades industriais. A vinda dos imigrantes para suprir a carência de braços, especialmente italianos e espanhóis, trouxe à classe operária em formação a doutrina anarquista que cedo atemorizou as elites dominantes com seus ideais de autonomia e de exterminio da sociedade burguesa.

Contra o pensamento liberal classista e o autoritarismo clerical, o anarquismo pugnou por uma sociedade de indivíduos solidários, livremente associados, capazes de cooperar e de agir conscientemente diante das mudanças sociais. Sendo a formação da consciência uma pedra angular da constituição de indivíduos livres, o 
movimento libertário preocupou-se invariavelmente com a educação dos trabalhadores e com a realização de experiências pedagogicamente inovadoras, calcadas nos princípios da educação integral e do ensino racionalista (Ghiraldelli Jr., 1987; Jomini, 1990). Insistindo na democratização do saber e opondo-se ao ensino religioso e ao ensino público-estatal, o método libertário anunciava, entre outros aspectos: a) o desenvolvimento de todas as faculdades intelectuais, psíquicas e corporais; b) a fundamentação no conhecimento científico, afastando a inverdade e a presunção moral; c) a vinculação ao trabalho, como atividade básica propulsora do ser humano; d) a co-educação entre sexos e classes sociais, para eliminação dos preconceitos e para mútuo aprendizado; e) a abolição de todo instrumento coercitivo, como provas e exames, e a aposta no estímulo como elemento vital do processo de auto-aprendizagem.

Tais concepções transpareceram nas ações de agitação e propaganda no interior do movimento operário, das quais a imprensa anarquista guarda o principal testemunho; ${ }^{3}$ orientaram igualmente as práticas culturais de massa por meio de conferências, festivais de teatro, poesia e literatura e outras festividades; pautaram, principalmente, as iniciativas libertárias originais no campo educacional, através dos centros de estudos, das escolas modernas livres e das universidades populares. ${ }^{4}$ Embora tenham sido objeto específico de um único trabalho no Rio Grande do Sul (Corrêa, 1987), essas realizações tiveram aqui especial relevância, não somente pela longevidade alcançada em alguns casos, mas pela influência singular do anarquismo nesse Estado (Petersen, 1979, 1995; Marçal, 1985).

É de se notar que as iniciativas das organizações operárias voltadas à escolarização e formação profissional dos trabalhadores - haja vista a desassistência pública - foram recorrentes e partilhadas no período igualmente pelos socialistas. No entanto, a liderança libertária no Rio Grande do Sul alcançou projeção nacional, como referência política e organizativa, e perdurou por mais tempo, diante da ascensão dos comunistas, tendo sido o último reduto do anarquismo ao final da República Velha. ${ }^{5}$ No Rio Grande do Sul, a ação libertária no campo da educação teria ademais sido beneficiada pelo positivismo de Borges de Medeiros, que subtraía a intervenção estatal na matéria e preconizava a liberdade de orientação nas escolas.

A propagação das práticas anarquistas encontrou até os anos 20 condições históricas favoráveis, cuja alteração a seguir veio a provocar o seu declínio. Entre elas, a relativa segregação e o confinamento a que estava submetido o incipiente proletariado na época (Manfredi, 1987) e a inatividade do poder público (Ghiraldelli Jr., 1987), cujo efeito conjugado foi tornar o operariado sensivel ao apelo utópico e crítico das diversas correntes revolucionárias. O processo de integração iniciado a

3 Destacando-se os periódicos A Luta, da Federação Operária do Rio Grande do Sul, e A Voz do Trabalhador, órgão da Confederação Operária Brasileira.

4 Essas diferentes frentes de atuação são comumente associadas às correntes anarco-sindicalista (ou sindicalistas revolucionários) e anarco-comunista (ou comunistas libertários). Seguindo opinião de Silva Jr. (1995a), preferimos evitar essas designações, ao que parece, empiricamente indevidas, ao menos até a década de 20.

5 Como bem atestam as deliberações do III e do IV Congresso Operário do Rio Grande do Sul, em meados dos anos 20 (cf. Norma, 1987, 101). 
partir dos levantes operários de 1917 e 1919, por meio da repressão das vanguardas e de ações reformistas dirigidas ao proletariado, terminaria por diluir as diferenças e conduzir à assimilação, por este, da visão hegemônica, preparando o terreno para o posterior atrelamento do Estado Novo.

Apenas esboçada pela literatura, conviria aprofundar essa hipótese no campo específico da formação, em que as escolas libertárias vêem-se progressivamente em disputa com ações inovadoras, como aquelas inspiradas na Pedagogia Nova, e com uma presença crescente do Estado, que conduziria nas décadas seguintes à instauração de um sistema escolar unificado. ${ }^{6}$ Esse novo cenário teria posto fim à possibilidade de um projeto de educação globalizante e classista, como o dos libertários.

Para bem compreender o desempenho dessas propostas concorrentes, seria necessário situá-los ao menos em dois eixos oblíquos de tensão e conflito, sobre os quais as organizações operárias, de um lado, disputaram a base operária entre si e, de outro, posicionaram-se como interloculores da mesma, construíram uma visão dos seus interesses que thes serviu de pauta para a negociação com a classe patronal e o Estado. Não se pode esquecer, por exemplo, que a direção das organizações operárias constitui uma posição de poder, não apenas em nome da classe, mas sobre esta, em relação à qual medidas de convencimento e de coação seguidamente se combinavam. ${ }^{7}$ No âmbito das práticas educativas, seria plausível igualmente indagar se o culto ao saber iluminista e a concepção notoriamente positivista da ciência, esposados pelos libertários, não teriam gerado um desprezo pela cultura popular operária e entrado em choque com a pedagogia não diretiva do "ensino mútuo". Até que ponto tais contradições, ou a impossibilidade de resolvê-las nas condições da época, não seriam explicativas do fim (por vezes repentino) das escolas e universidades populares?

A clarificação desse campo de disputas permitiria situar multilateralmente os agentes e avaliar a razão e o alcance de suas estratégias de posição, rompendo com certa hipóstase que o discurso de uns e outros, tomados como expressão da realidade ou da sua prova em negativo, tende a produzir. Ao dizê-lo, quer-se assinalar duas dificuldades da literatura, de resto apontadas em outras análises (Silva Jr., 1994), que conduzem a indiferenciar a visão produzida por um agente, de sua efetiva atuação histórica. De um lado, o tema da formação sindical e operária em geral carece quase absolutamente de fontes primárias, orais e escritas, de modo que a inferência sobre o valor explicativo dos poucos registros encontrados tende a extrapolar o seu real conteúdo histórico, como forma de suprir as lacunas empiricas. Em seguida, como essas fontes provêm dos protagonistas da ação em estudo, e por serem raras são preciosas, sem a cautelosa mediação da análise crítica das fontes recai-se em sua reificação. Uma iniciativa de formação libertária passa a ter importância (benéfica) porque assim o afirmam seus idealizađores (em depoimentos, em artigos da imprensa, em documentos das escolas livres, etc.) e não porque se disponha de dados sobre a sua repercussão social e seus efeitos sobre a cultura dos trabalhadores.

6 Ver a respeito o texto de Flávia Werle, nesta Revista.

7 O mecanismo de associação compulsória aos sindicatos dos calceteiros, como forma de aceder ao mercado de trabalho, constitui disto uma boa ilustração (cf. Silva Jr., 1995b). 
Os poucos trabalhos dedicados à ação educativa dos anarquistas no Rio Grande do Sul têm o mérito de haver encontrado e sistematizado os parcos registros empíricos disponiveis, além de buscarem (Norma, 1987) confrontar as caracteristicas dessas experiências com o próprio ideário anarquista. Para que se avalie a sua influência na formação da classe operária, ${ }^{8}$ além de igual procedimento em relação a iniciativas menos conhecidas e de agregar novos registros empíricos, faz-se necessário extrapolar a análise das organizações e adentrar a realidade dos operários, com seus referentes culturais e suas lógicas de ação. os quais encontram na representação de classe apenas um dos seus pontos de apoio. Ao reconstituir essas categorias sociais em suas trajetórias, é mister portanto entendê-las como um pólo ativo (ou ao menos reativo) na contenda entre os vários agentes, internos e externos à classe operária, que a desejam formar.

\section{Referências bibliográficas}

CORREA, Norma. Os libertários e a educação no Rio Grande do Sul (1895-1926). Dissertação de Mestrado (Educação), UFRGS, 1987.

GHIRALDELLI Jr, Paulo. "Movimento operário e educação popular na Primeira República”. Cadernos de Pesquisa (São Paulo), n. 57, p. 30-8, 1986.

- Educação e movimento operário. São Paulo: Cortez/Autores Associados, 1987.

JOMINI, Regina. Uma educação para a solidariedade. Campinas: Pontes, 1990.

MANFREDI, Silvia. Formação sindical; história de uma prática culturaì no Brasil. São Pauio: Escrituras Editora, 1996.

MARÇAL, João Batista. As primeiras lutas operárias no Rio Grande do Sul. Porto Alegre: Globo, 1985.

PETERSEN, Sílvia. “As greves no Rio Grande do Sul (1890-1919)”. In: DACANAL, José, GONZAGA, Sergius (Orgs.). RS: economia e política. Porto Alegre: Mercado Aberto, 1979, p. 277-327.

- .Cruzando fronteiras: as pesquisas regionais e a história operária brasileira". Anos 90 (Porto Alegre), n. 3, p. 129-53, 1995.

SILVA Jr., Adhemar. "História regional e operariado: o caso da produção recente sobre a Primeira República”. Veritas (Porto Alegre), v. 39, n. 154, p. 271-282, 1994.

- "Anarco-sindicalismo no Brasil; notas sobre a produção de um mito históricohistoriográfico". In: D’ANGELO, Ana (Org.) Histórias de trabalho: Porto Alegre: Unidade Editorial, 1995a, p. 151-9.

- "Contribuição a uma 'História dos de baixo' do sindicalismo". Estudos Ibero-Americanos, Porto Alegre, v. 21, n. 1, p. 61-83, $1995 \mathrm{~b}$.

8 Tema ainda controverso, também no que tange à influência politica das diversas correntes do movimento operário. 